\title{
Hands Free Technique: New Tool Possibility for Image Capture of Sublingual Microcirculation with Handheld Vital Microscopy - HVM
}

\author{
Técnica de Manos Libres: Nueva Posibilidad de Herramienta para Capturar \\ imágenes de Microcirculación Sublingual con Microscopía Vital Portátil-HVM
}

José Custódio Feres Vieira

VIEIRA, J. C. F. Hands free technique: new tool possibility for image capture of sublingual microcirculation with handheld vital microspopy - HVM. Int. J. Odontostomat. 15(1):181-188, 2020.

\begin{abstract}
New microcirculatory imaging techniques allowed direct observation of microcirculation at the bedside. This study presents a new device that assists the operator with the unprecedented Hands Free technique. To this end, a replica of Handheld Vital Microscopy was developed to simulate the method of capturing the image in the sublingual area, the most used site to assess microcirculation in critically ill patients. We achieved a reduction in the displacement of microscope replica with a Hands Free method. The immediate consequence is an increase in the stability of HVM replica by 75 times, or more, over the current 4 seconds, during its contact with the sublingual tissue. The device also offers better control of the pressure of the tip of the HVM replica over the sublingual area. The results demonstrated that the Hands Free technique, operating in the same sublingual area for 900 seconds, should allow for future research aimed at therapeutic maneuvers in patients with serious illnesses.
\end{abstract}

KEY WORDS: hands free technique, stabilizer, HVM imaging, artefacts, sublingual, microcirculation, SDF imaging, IDF imaging.

\section{INTRODUCTION}

The central function of microcirculation is the exchange of oxygen and nutrients between the intravascular and adjacent cells (Tsai et al., 2003). Microcirculation is the set of capillary vessels, arterioles and venules with a diameter of less than 100 micrometers (Ince, 2005). As the change in microcirculation precedes that in macrocirculation (Trzeciak \& Rivers, 2005), it seems sensible to monitor this organ and, if necessary, improve its function (Elbers \& Ince, 2006).

To study microcirculation, a table microscope was developed, using the Incident Dark-Field Illumination method (Sherman et al., 1971). In the late 1990s, the first HVM (Handheld Vital Microscopy) was created under the name of OPS (Orthogonal Polarization Spectral) which, in addition to being portable, allows direct view of microcirculation (Groner et al., 1999). After OPS came other generations of HVM, such as: SDF, Sidestream Dark Field (Goedhart et al., 2007) and, the most recent, CytoCam (Aykut et al., 2015), an IDF-based device.

The clinical introduction of new microcirculatory imaging techniques allowed direct observation of microcirculation at the bedside of the patient. The sublingual area is the most used site to assess microcirculation in critically ill patients (Ince et al., 2018).

However, the prerequisite for the microcirculation assessment, using HVM imaging, is to ensure measurements free of artifacts (Massey \& Shapiro, 2016).

\footnotetext{
${ }^{1}$ Programa de Pós Graduação, PPG Ciência Cirúrgica Interdisciplinar, Universidade Federal de São Paulo (Unifesp), São Paulo, Brasil.
} 
However, there is a logistical challenge for acquiring the image of sublingual microcirculation, considering that HVM is distanced from the base by a cable, keeping the camera stable with the hands in the sublingual area in the correct position, and fixing the view of microcirculation on the computer screen. And, at the same time, with the other hand, clicking on the computer keyboard to start, while recording the video that shows precise results, which is not an easy task. (Massey \& Shapiro).

The acceptable vídeo duration, without moving the microcirculation image, in the usual technique (Hands On) is 4 to 20 seconds, which is already considered laborious (Ince et al., 2018), once the duration and stability of the video images go together (van Elteren et al., 2015).

The justification for this study emerged in the Second Consensus on the evaluation of sublingual microcirculation in critically ill patients: results of a task force of European Society for Intensive Care Medicine. In future perspectives, the study mentions the need to create a tool in which the operator can monitor their patient's microcirculation for a longer period.

Challenge: How will the doctor be able to keep HVM stable for a long time, holding it with his/her hands? In this scenario, the focus of this study was to develop a support tool to enable the use of HVM in Hands Free technique. It seems to be a resource that could innovate and improve the capture of sublingual image in humans for longer periods, thus enhancing the knowledge in microcirculation analysis.
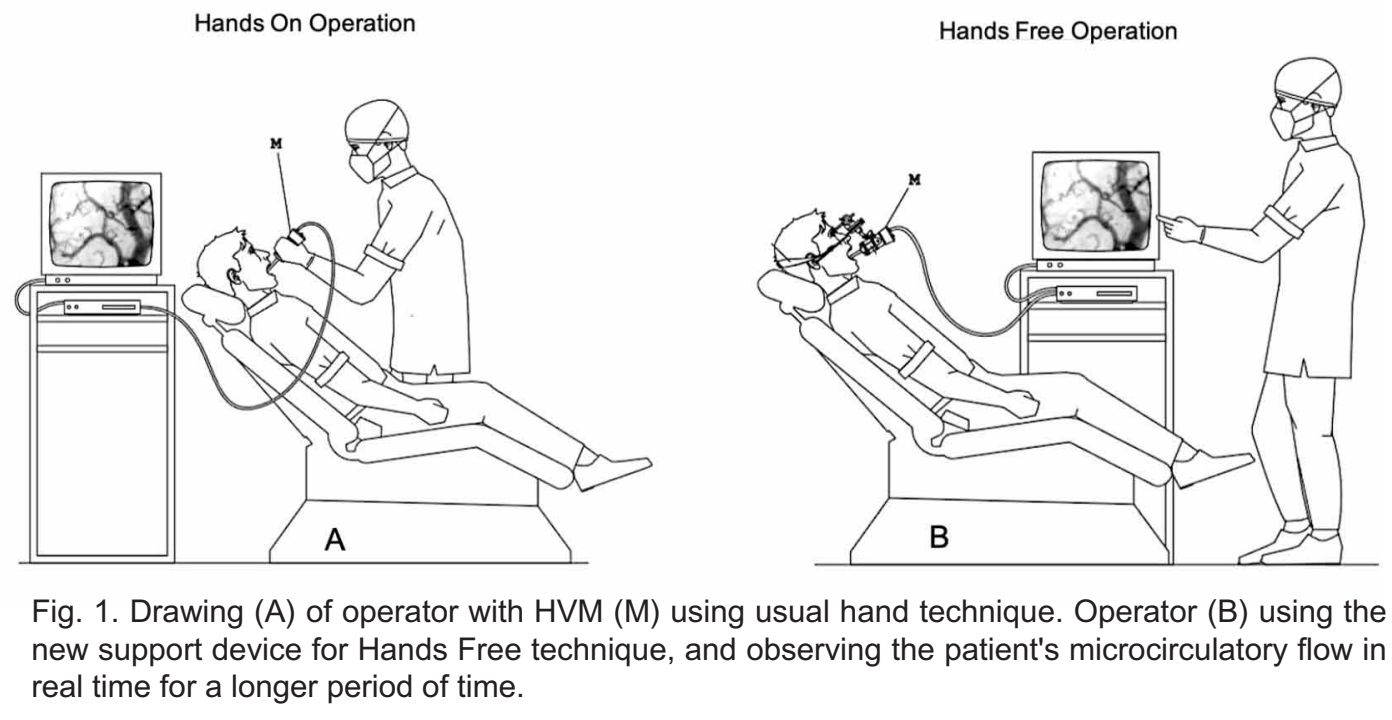

Fig. 1. Drawing (A) of operator with HVM (M) using usual hand technique. Operator $(B)$ using the new support device for Hands Free technique, and observing the patient's microcirculatory flow in real time for a longer period of time.
The aim of this work was to develop a tool that allows healthcare professional to operate hands-free, using Handheld Vital Microscopy or similar.

\section{MATERIAL AND METHOD}

The focus of this study is to develop a tool that allows healthcare professionals to use the unprecedented Hands Free technique (Figs. 1 and 2). For this, a replica of an aluminum HVM (Fig. 3, 4 and 5) was created, with a diameter of $23 \mathrm{~mm}$, length $220 \mathrm{~mm}$ and weight $120 \mathrm{~g}$, similar to IDF (Aykut et al.). The choice of IDF as a replica was made because it is the latest generation of microscope, in addition to being considered superior to its predecessor SDF (Gilbert-Kawai et al., 2016).

To measure the displacement of HVM replica, the Sensor Kinetcs application was used on the cell phone. It will capture possible changes in movement, every second (Fig. 6). The accelerometer was the sensor chosen to test the acceleration along a certain axis. The sensor measures the displacements caused by the operator, when holding HVM replica, using the conventional or Hands On technique, versus the Hands Free technique (Fig. 1).

To carry out such an experiment, a magnetic base was attached to the back of the replica, where the cell phone was fixed (Fig. 7A). 


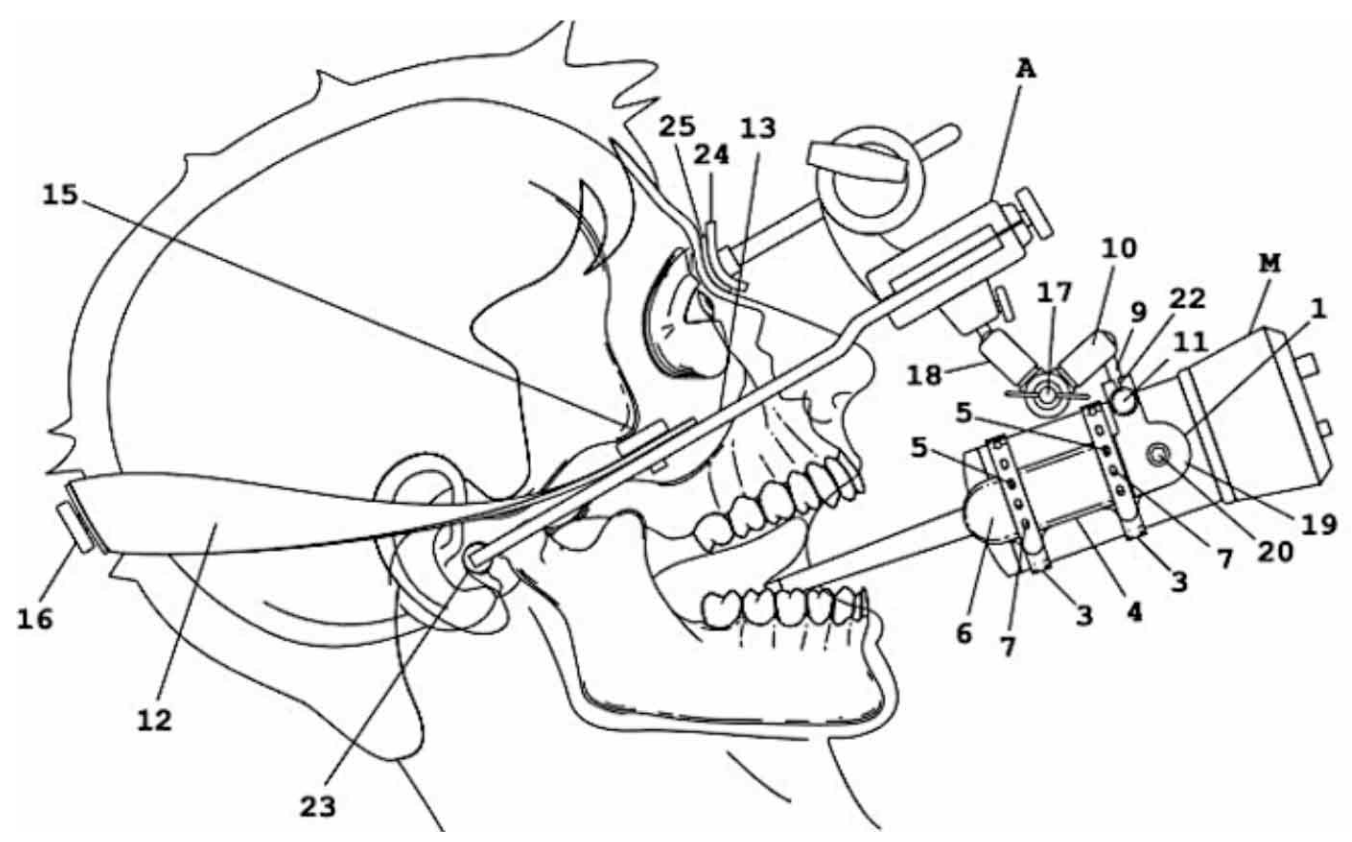

Fig. 2. Comprises a facial arch $(A)$ characterized by receiving a flat support (1), preferably elliptical in shape, provided with a concave central recess (2) that configures a seat for a sublingual microscope (M), which houses on said central concave recess (2) of the support (1); said support (1) is provided with two locking straps (3) that project from the side (4) of the support (1), surrounding the outer perimeter of sublingual microscope body (M), and said locking straps (3) they are long enough to surround the entire outer perimeter of the microscope $(M)$ and reach locking pins (5) that protrude from the flat surface (6) of the support (1); the locking straps (3) have elasticity and are provided with a sequence of holes (7) that communicate with the locking pins (5) and promote the attachment of the microscope (M) to the support (1); the support (1) receives a perpendicular adapter (19) fixed by a screw (20) to the hole (21), said perpendicular adapter (9) has a rectangular seat (8) with a side slot (22), which receives and houses the cylindrical axis (9) of a lower articulated arm (10) of the facial arch (A), said axis (9) has the flattened end containing a transverse screw with handle (11); the flat end of cylindrical shaft (9) is fixed using the clamping knob (11) which is transversely attached to the slot in the rectangular seat (8) of the perpendicular adapter (19) fixed on the flat surface (6) of the support (1); the extra-oral accessory has a second means of fixation, composed of an adjustable headband (12) attached to the facial arch device (A) on the stems (13) of the auricles, and said stems (13) have holes (14) that they receive fixing screws (15), adding said cranial strap (12) to the structure of the facial arch device (A), the cranial strap (12) being adjustable and provided with a rotating element (16) to adjust the tension around the head of the patient who acts together with the nasal support (24) coated with a silicone cushioning layer (25); once the microscope (M) is attached to the support (1) through the locking straps (3) and pins (5), and the whole is attached to the facial arch device (A) by fixing the axis (9) of the articulated arm lower (10) to the support (1), the data reading position is selected in patient's sublingual region and the locking means (17) of the lower (10) and upper (18) articulated arms is activated, locking the position of the set. This work generated a patent application number BR102018077323.

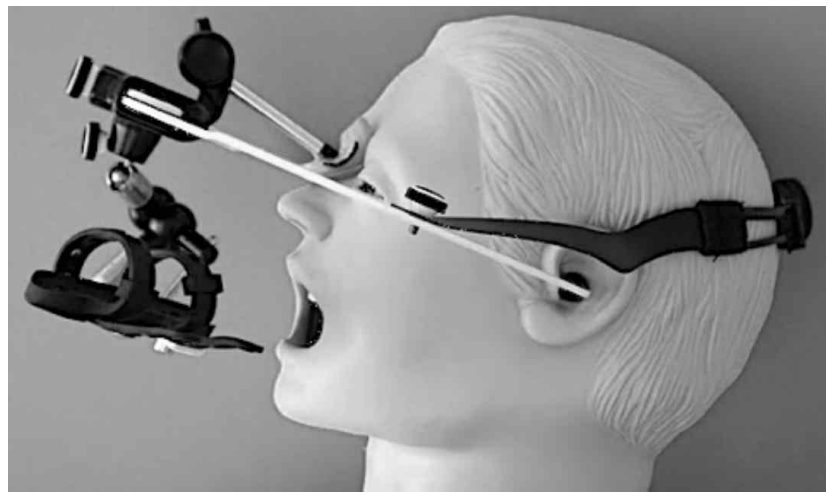

Fig. 3. Support tool tested on a dummy for the Hands Free technique.

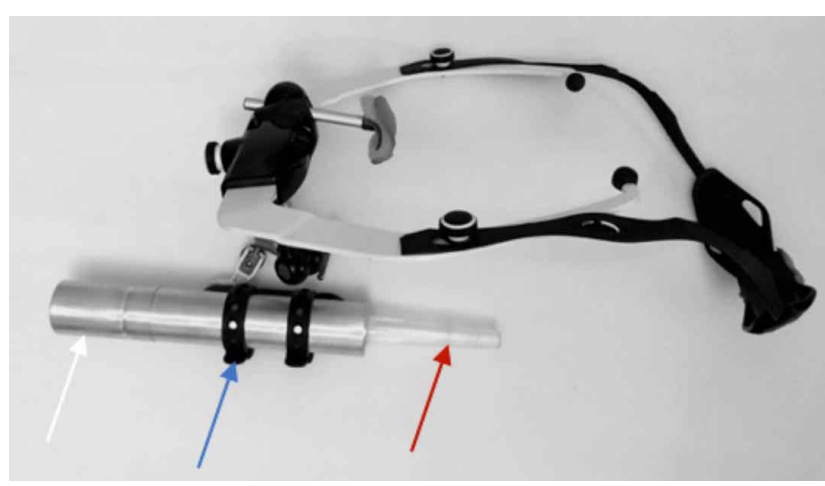

Fig. 4. Replica of HVM (white arrow), adjustable rubber clamps for HVM (blue arrow) and disposable plastic cover, similar to the original (red arrow). 


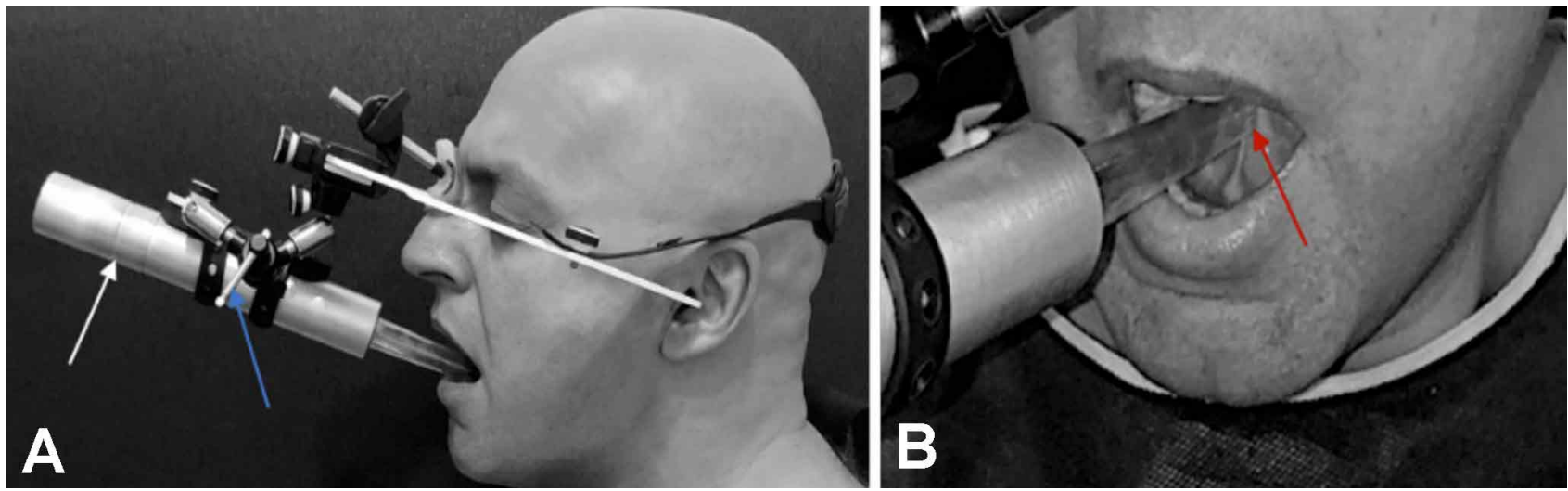

Fig. 5. (A) Replica of HVM (white arrow) in position, after adjustment and locking (blue arrow) of the articulated arm, simulating the Hands Free technique. Sublingual area in greatest increase (B), observe the tip of disposable plastic cap against the desired area (red arrow)
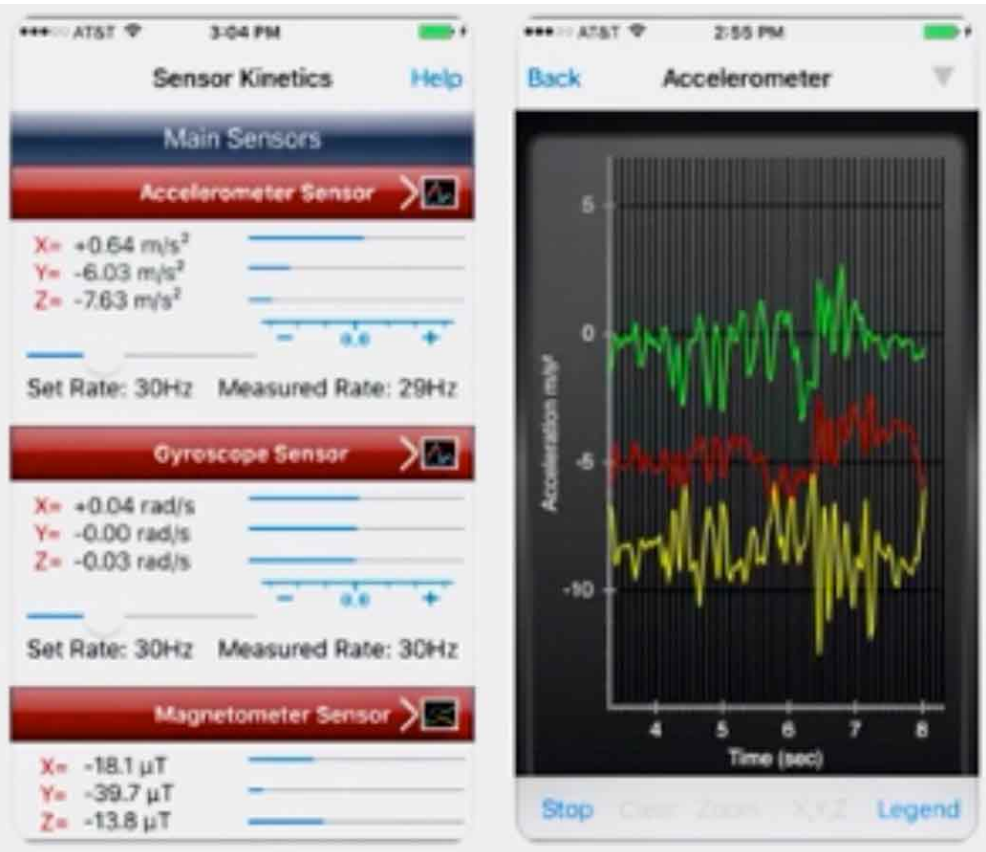

\begin{tabular}{|c|c|c|c|c|}
\hline \multicolumn{2}{|c|}{ tet ATST $\%$} & \multicolumn{2}{|c|}{$323 \mathrm{Fm}$} & \multirow[t]{2}{*}{$=$} \\
\hline Back & \multicolumn{3}{|c|}{ Lin_Ace: 145 samples } & \\
\hline a & Tine & $X$ value & r value & $Z$ walse \\
\hline 1 & 0621 & 0.2430 & 0.1908 & -06087 \\
\hline 2 & Qusi & 0.1955 & 00411 & 0.0578 \\
\hline 3 & 0 cete & couss & 00693 & 0.1950 \\
\hline 4 & a.121 & 0.1046 & 0.2563 & 0.0024 \\
\hline 5 & atsi & 0.0526 & 00690 & 0,6639 \\
\hline 6 & 0.106 & -0.198 & Q.4esi & -0.0023 \\
\hline 7 & 0.221 & -0.0488 & .00535 & $=0.1411$ \\
\hline$B$ & 0.251 & $.0+1029$ & 0.0412 & -0.0522 \\
\hline 9 & 0.280 & -00060 & -0.0438 & .0 .1054 \\
\hline 10 & 0.21 & -00078 & 0.1225 & .00912 \\
\hline$\pi$ & 0351 & 0.0058 & 0.1212 & -0.1178 \\
\hline 12 & 0396 & $-003 \times 0$ & 00784 & -00623 \\
\hline 13 & 0416 & -02539 & -0.0917 & -02029 \\
\hline 14 & 0.451 & .06581 & .0457 & $-0.506 ?$ \\
\hline 15 & 0.486 & .0 .8546 & .05882 & -0.7221 \\
\hline 16 & 0521 & $-0 \times 580$ & 0.0552 & -0.9090 \\
\hline 17 & 0.551 & $-0.17 n$ & 00620 & 0.1605 \\
\hline 18 & 0.586 & 0.3660 & 0.4592 & 0.7006 \\
\hline 19 & 6016 & Q.945 & 0.8114 & Q 3529 \\
\hline
\end{tabular}

Fig. 6. Example of application showing the $x, y, z$ axes: on the left, in the center, the accelerometer graphs, and numerical data on the right.

The numerical data are on the $\mathrm{x}, \mathrm{y}$ and $\mathrm{z}$ axes, where 5 measurements were performed for each technique in all periods. The chosen periods were 0 , $5,10,20,60,120,180,240,300,600,900$ seconds.

For statistical analysis, the following softwares were used: SPSS V20, Minitab 16 and Excel Office 2010.

For this work, a significance level of 0.05 (5\%) was defined. The confidence intervals adopted in this work were constructed with a $95 \%$ statistical level.
There was a normal distribution, whose quantitative variables of the main outcome were determined using Kolmogorov-Smirnov test (KS)

The purpose is to compare the displacements around each of the three axes ( $x, y$ and $z$ ), in HANDS ON versus HANDS FREE scenarios at specific times. As the data are paired, that is, the same subject is his own research and control, T-Student test was used. At each selected time, the first 10 observations were collected and compared. Finally, the displacements of the three axes, in modules, were added for a general measure. 

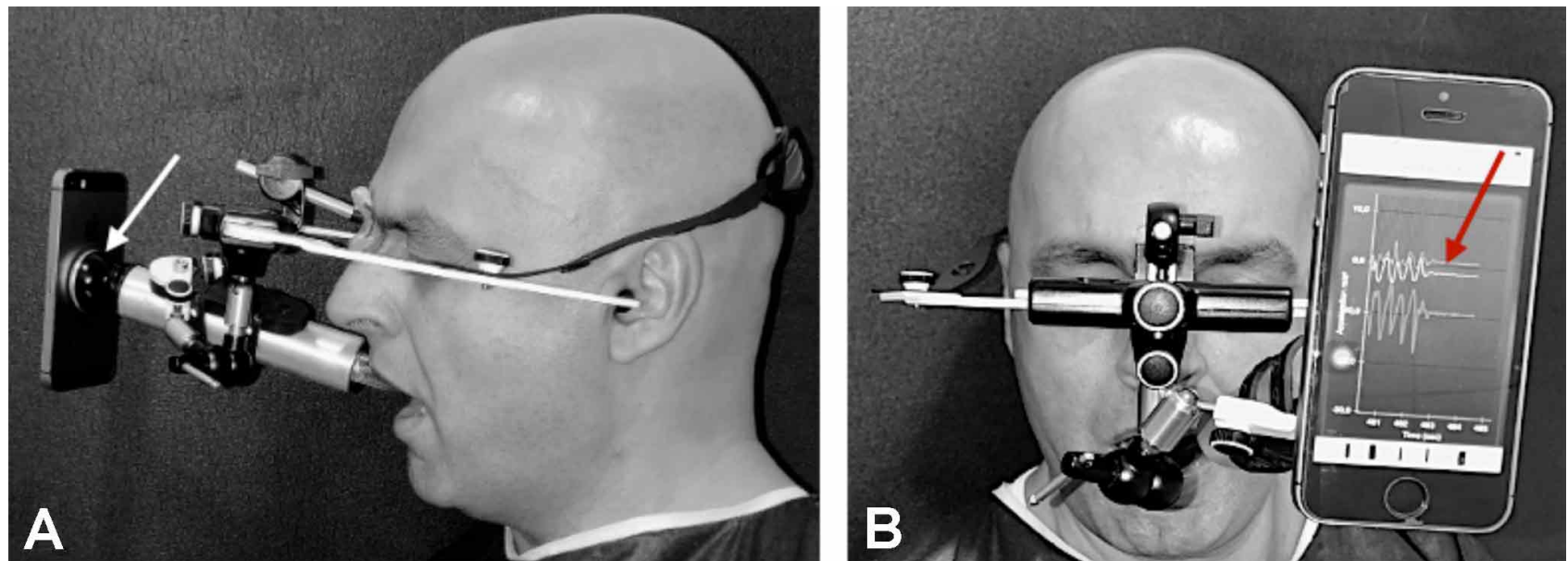

Fig. 7. (A) Cell phone attached to a magnetic device installed at the rear of HVM replica (white arrow) to measure displacements.

(B) Cell phone screen displays initial changes to $\mathrm{x}, \mathrm{y}, \mathrm{z}$ axes and then the same stabilized axes (red).

\section{RESULTS}

The results show that it is perfectly feasible to create a device to support the use of Hands Free technique. The facial arch has been used in the dental field for years, which ensures safety in clinical use (Fig. $5 A)$.

In calculating the total displacement on the three axes (Table I; Fig. 8), Hands Free technique was always less than the average in the situation of Hands On technique. The biggest difference occurs in 20 seconds, where the average was 0.63124 Hands Free and 0.09509 Hands On ( $p$-value <0.001)

\section{Positive points:}

1. After adjusting the arc opening (P, M, G), adjusting the nasal support and stabilization strap on the user's head, the whole set remains stable (Fig. 3)

2. Enables the attachment of any HVM or similar, as the rubber straps are adjustable (Fig. 4).

3. Lockable articulated arms allow the operator to choose the best sublingual area (Fig. 5A).

4. The user can move the neck smoothly and HVM replica tends to be stable

5. Hands free technique has a smaller displacement than the Hands On technique, with a statistically significant difference.

6. Enables greater control of pressure exerted by the

\section{DISPLACEMENT}

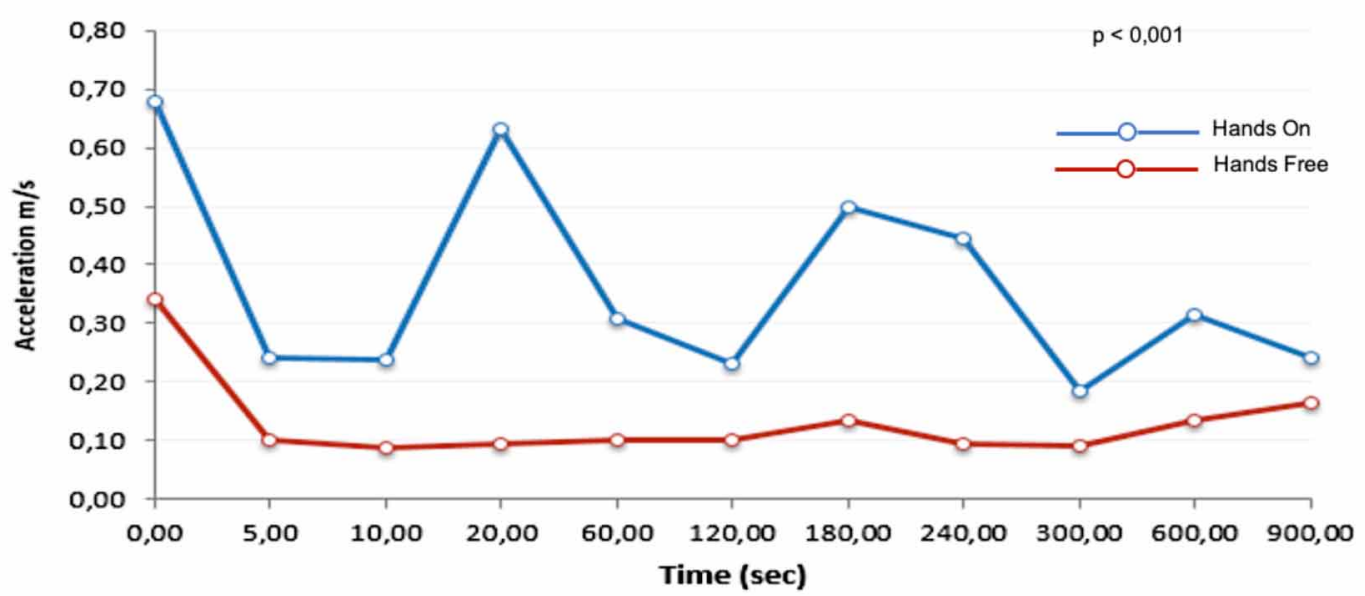

Fig. 8. Graph shows greater stability of displacement of HVM replica in Hands Free technique (red line), when compared to Hands On technique (blue line). 
Table I. Calculations of displacement of the three $\mathrm{x}, \mathrm{y} z$ axes data obtained by Sensor Kintcs application.

\begin{tabular}{|c|c|c|c|c|c|c|c|c|c|}
\hline \multicolumn{2}{|c|}{ Displacement } & \multirow{2}{*}{$\begin{array}{c}\text { Average } \\
0,67825\end{array}$} & \multirow{2}{*}{$\begin{array}{c}\text { Median } \\
0,68066\end{array}$} & \multirow{2}{*}{$\begin{array}{c}\begin{array}{c}\text { Standard } \\
\text { deviation }\end{array} \\
0,32002\end{array}$} & \multirow{2}{*}{$\frac{\text { Minimum }}{0,09231}$} & \multirow{2}{*}{$\begin{array}{c}\text { Maximum } \\
1,55270\end{array}$} & \multirow{2}{*}{$\frac{n}{50}$} & \multirow{2}{*}{$\frac{\mathrm{Cl}}{0,08870}$} & \multirow{3}{*}{$\frac{\text { p-value }}{<0,001}$} \\
\hline $0 \mathrm{cos}$ & Hands On & & & & & & & & \\
\hline sec. & Hands Free & 0,34236 & 0,15945 & 0,39588 & 0,04937 & 2,03678 & 50 & 0,10973 & \\
\hline \multirow{2}{*}{5 sec. } & Hands On & 0,24054 & 0,23214 & 0,08629 & 0,05411 & 0,43229 & 50 & 0,02392 & \multirow{2}{*}{$<0,001$} \\
\hline & Hands Free & 0,10136 & 0,10270 & 0,03524 & 0,02123 & 0,18643 & 50 & 0,00977 & \\
\hline \multirow{2}{*}{$10 \mathrm{sec}}$. & Hands On & 0,23929 & 0,19480 & 0,14468 & 0,03201 & 0,62020 & 50 & 0,04010 & \multirow{2}{*}{$<0,001$} \\
\hline & Hands Free & 0,08654 & 0,09171 & 0,03207 & 0,03382 & 0,16220 & 50 & 0,00889 & \\
\hline \multirow{2}{*}{$20 \mathrm{sec}}$. & Hands On & 0,63124 & 0,29545 & 0,61833 & 0,07024 & 2,24025 & 50 & 0,17139 & \multirow{2}{*}{$<0,001$} \\
\hline & Hands Free & 0,09509 & 0,09992 & 0,03537 & 0,01302 & 0,18711 & 50 & 0,00980 & \\
\hline \multirow{2}{*}{$60 \mathrm{sec}}$. & Hands On & 0,30795 & 0,24648 & 0,20373 & 0,06863 & 0,91910 & 50 & 0,05647 & \multirow{2}{*}{$<0,001$} \\
\hline & Hands Free & 0,09964 & 0,09867 & 0,02923 & 0,03265 & 0,17065 & 50 & 0,00810 & \\
\hline \multirow{2}{*}{$120 \mathrm{sec}}$. & Hands On & 0,23092 & 0,21645 & 0,10126 & 0,03686 & 0,55165 & 50 & 0,02807 & \multirow{2}{*}{$<0,001$} \\
\hline & Hands Free & 0,09992 & 0,11224 & 0,04442 & 0,02292 & 0,18424 & 50 & 0,01231 & \\
\hline \multirow{2}{*}{$180 \mathrm{sec}}$. & Hands On & 0,49873 & 0,27941 & 0,54757 & 0,09024 & 2,00252 & 50 & 0,15177 & \multirow{2}{*}{$<0,001$} \\
\hline & Hands Free & 0,13515 & 0,11141 & 0,08130 & 0,03110 & 0,31594 & 50 & 0,02254 & \\
\hline \multirow{2}{*}{$240 \mathrm{sec}}$. & Hands On & 0,44551 & 0,40865 & 0,32089 & 0,07472 & 1,90923 & 50 & 0,08894 & \multirow{2}{*}{$<0,001$} \\
\hline & Hands Free & 0,09591 & 0,08492 & 0,03459 & 0,02378 & 0,16593 & 50 & 0,00959 & \\
\hline \multirow{2}{*}{$300 \mathrm{sec}}$. & Hands On & 0,18405 & 0,14775 & 0,11579 & 0,03168 & 0,53479 & 50 & 0,03210 & \multirow{2}{*}{$<0,001$} \\
\hline & Hands Free & 0,08987 & 0,09085 & 0,04028 & 0,02374 & 0,17433 & 50 & 0,01116 & \\
\hline \multirow{2}{*}{600 sec. } & Hands On & 0,31626 & 0,27639 & 0,12311 & 0,17112 & 0,76977 & 40 & 0,03815 & \multirow{2}{*}{$<0,001$} \\
\hline & Hands Free & 0,13488 & 0,13488 & 0,05065 & 0,02748 & 0,25810 & 40 & 0,01570 & \\
\hline \multirow{2}{*}{$900 \mathrm{sec}}$. & Hands On & 0,24276 & 0,24042 & 0,06054 & 0,13765 & 0,32504 & 10 & 0,03752 & \multirow{2}{*}{0,010} \\
\hline & Hands Free & 0,16399 & 0,15554 & 0,03554 & 0,12641 & 0,22688 & 10 & 0,02203 & \\
\hline
\end{tabular}

tip of HVM on the tissue to be analyzed (Fig. 5B); which is likely to decrease the pressure artifacts on the microcirculatory flow. Common artifact in capturing the microcirculatory image (Ince et al., 2018).

7. Facial arch and autoclavable ear supports

\section{Negative points:}

1. The support system for Hands Free technique must be adjusted sparingly to find the best fit. This requires the operator's sensitivity to adjustments of nasal and ear support to avoid creating discomfort.

2. Non-autoclavable items: 3,12, 25 (Fig. 2). Requires cleaning and disinfection

\section{DISCUSSION}

The methods of image capture existing in the real world are not perfect, as they are subject to extra elements, missing elements, or even translation errors that cause defects - the so-called image artifacts
(Spaide et al., 2015). With standardization in the capture of microcirculatory image, such artifacts would be avoided, which would ensure an adequate analysis of blood flow (Massey \& Shapiro). Therefore, it is necessary to take into account that the use of any monitoring device to measure the physiological variables, as well as the use of measurements generated by HVM, requires skill and training of the operator (Ince et al.).

In the case of HVM, the user holds the video microscope with their hands and manually adjusts the focus and lighting. He must keep the tip of the microscope firm - around less than $0.1 \mathrm{~mm} / \mathrm{s}$ of lateral movement - when touching the tissue, and without applying pressure to avoid obstruction of the flow (Massey et al., 2013). Meanwhile, the operator monitors the operation on a video monitor.

With this logistical challenge, some studies that evaluated the sublingual microcirculatory flow in critically ill patients showed that, in 240 clips analyzed, 86 obtained pressure artifacts and only 74 showed excellent quality (Sallisalmi et al., 2012). The study 
on the impact of video quality on the sublingual microcirculatory image in critically ill patients, analyzed 2455 videos; of these, only $56 \%$ were considered acceptable (Damiani et al., 2017). The article that analyzed the efficiency of two software for the analysis of microcirculation discarded 356 of 440 videos analyzed, as they are not of excellent quality. Studies show that the software's analysis accuracy is directly related to image quality. And therefore, to obtain acceptable results, the prerequisite is high-quality software (Carsetti et al., 2017).

Some technical options have been proposed in order to reduce image artifacts. A vacuum tip was created to suck the mucosal surface to reduce pressure artifacts and increase stability (Balestra et al., 2010). But in practice, it is scarcely used (Massey \& Shapiro). Another device that contributes to digitization operations during the recording of images is the pedal controls that replace the manual click on the computer (Massey \& Shapiro). This operation is not considered hands free because the operator's hands remain occupied with the camera. With that, it is evident that image artifacts are the great villain in the capture and analysis of microcirculatory videos, and an obstacle in the research of sublingual microcirculation. A recent article points to hope for a future improvement in the capture of such images. The technique employs optical coherence tomography (OCTA) angiography (Hessler et al., 2020). This new method makes it possible to avoid pressure artifacts; but, as known, it is also subject to other types of image artifacts (Spaide et al.).

After 10 years of the First Consensus (De Backer et al., 2007), more than 600 clinical and experimental articles with HVM have been published. A task force from the European Society for Critical Care Medicine recently published the Second Consensus on the assessment of sublingual microcirculation in critically ill patients.

Necessary statements were carried out for the acquisition and interpretation of images acquired from the sublingual microcirculation (Ince et al.). In the same Consensus, in future perspectives, two sentences justified the intention to develop the tool with support from HVM:

"35. Tools should be developed to make pressure-artifact-free measurements and allow singlespot measurements to be made during a therapeutic maneuver".
"37. Technology should be developed to allow stable measurements to be made for longer periods of time to allow continuous measurement during, for example, a therapeutic maneuver allowing observation of single vessels response before and after intervention".

Such evidence indicates that this study may contribute to the development of an unprecedented technique called Hands Free. It is a tool (Fig. 3) that aims to couple HVM (SDF, IDF or similar) to increase stability for a longer period, increasing the time by 75 times, or more, compared to current capture - 4 seconds - by the technique usual Hands on (Ince et al.). The limitations of this work refer to the use of a HVM replica . Further studies will be necessary comparing the benefits of Hands Free technique offered to health professional, with the sublingual microcirculatory image generated by original HVM in patients.

Microcirculation has been studied in the pathophysiology of sepsis, heart failure and hypovolemia (Donati et al., 2013). Therefore, information about microcirculatory perfusion would be of great interest in intensive care to predict results and potentially guide therapy.

\section{CONCLUSION}

This study resulted in the development of a device that will benefit HVM stabilization technique (SDF, IDF or similar). It was designed to assist healthcare professionals and reduce image artifacts generated by the usual technique. Such a device allows the operator a longer time to stabilize HVM, for a longer period, thanks to unprecedented Hands Free technique, which allows future research aiming at therapeutic maneuvers in patients with serious diseases. More tests will be needed to validate the use of this system with the capture of microcirculation.

VIEIRA, J. C. F. Técnica de manos libres: nueva posibilidad de herramienta para capturar imágenes de microcirculación sublingual con microscopía vital portátil - HVM. Int. J. Odontostomat. 15(1):181-188, 2021.

RESUMEN: Las nuevas técnicas de imagen microcirculatoria permitieron la observación directa de la microcirculación junto a la cama del paciente. Este 
estudio sin precedentes presenta un nuevo dispositivo que ayuda al operador con la técnica manos libres. Con este fin, se desarrolló una réplica de la Microscopía Vital Portátil para simular el método de captura de la imagen en el área sublingual, el sitio más utilizado para evaluar la microcirculación en pacientes críticos. Logramos una reducción en el desplazamiento de la réplica del microscopio con el método de manos libres. La consecuencia inmediata es un aumento en la estabilidad de la réplica de HVM en 75 veces, o más, durante los 4 segundos actuales, durante su contacto con el tejido sublingual. El dispositivo también ofrece un mejor control de la presión de la punta de la réplica de HVM sobre el área sublingual. Los resultados demostraron que la técnica de manos libres, que opera en la misma área sublingual durante 900 segundos, debería permitir futuras investigaciones destinadas a maniobras terapéuticas en pacientes con enfermedades graves.

PALABRAS CLAVE: técnica manos libres, estabilizador, imagen HVM, artefactos, sublingual, microcirculación, imagen SDF, imagen IDF.

\section{REFERENCES}

Aykut, G.; Veenstra, G.; Scorcella, C.; Ince, C. \& Boerma, C. CytocamIDF (incident dark field illumination) imaging for bedside monitoring of the microcirculation. Intensive Care Med. Exp., 3(1):40, 2015.

Balestra, G. M.; Bezemer, R.; Boerma, E. C.; Yong, Z. Y.; Sjauw, K. D.; Engstrom, A. E.; Koopmans, M. \& Ince, C. Improvement of sidestream dark field imaging with an image acquisition stabilizer. BMC Med. Imaging, 13:10-15, 2010.

Carsetti, A.; Aya, H. D.; Pierantozzi, S.; Bazurro, S.; Donati, A.; Rhodes, A. \& Cecconi, M. Ability and efficiency of an automatic analysis software to measure microvascular parameters. J. Clin. Monit. Comput., 31(4):669-76, 2017

Damiani, E.; Ince, C.; Scorcella, C.; Domizi, R.; Carsetti, A.; Mininno, N.; Pierantozzi, S.; Adrario, E.; Romano, R.; Pelaia, P.; et al. Impact of microcirculatory video quality on the evaluation of sublingual microcirculation in critically ill patients. J. Clin. Monit. Comput., 31(5):981-8, 2017.

De Backer, D.; Hollenberg, S.; Boerma, C.; Goedhart, P.; Büchele, G.; Ospina-Tascon, G.; Dobbe, I. \& Ince, C. How to evaluate the microcirculation: report of a round table conference. Crit. Care, 11(5):R101, 2007.

Donati, A.; Domizi, R.; Damiani, E.; Adrario, E.; Pelaia, P. \& Ince, C. From macrohemodynamic to the microcirculation. Crit. Care Res. Pract., 2013:892710, 2013.

Elbers, P. W. G. \& Ince, C. Mechanisms of critical illness--classifying microcirculatory flow abnormalities in distributive shock. Crit. Care, 10(4):221, 2006.

Gilbert-Kawai, E.; Coppel, J.; Bountziouka, V.; Ince, C.; Martin, D. \& Caudwell Xtreme Everest and Xtreme Everest 2 Research Groups. A comparison of the quality of image acquisition between the incident dark field and sidestream dark field video-microscopes. BMC Med. Imaging, 16:10, 2016.
Goedhart, P. T.; Khalilzada, M.; Bezemer, R.; Merza, J. \& Ince, C. Sidestream Dark Field (SDF) imaging: a novel stroboscopic LED ring-based imaging modality for clinical assessment of the microcirculation. Opt. Express, 15(23):15101-14, 2007.

Groner, W.; Winkelman, J. W.; Harris, A. G.; Ince, C.; Bouma, G. J.; Messmer, K. \& Nadeau, R. G. Orthogonal polarization spectral imaging: a new method for study of the microcirculation. Nat. Med., 5(10):1209-12, 1999.

Hessler, M.; Nelis, P.; Ertmer, C.; Alnawaiseh, M.; Lehmann, F.; Schmidt, C.; Kampmeier, T. G.; Rehberg, S. W.; Arnemann, P. H. \& Rovas, A. Optical coherence tomography angiography as a novel approach to contactless evaluation of sublingual microcirculation: A proof of principle study. Sci. Rep., 10:5408, 2020.

Ince, C. The microcirculation is the motor of sepsis. Crit. Care, 9(Suppl. 4):S13-9, 2005.

Ince, C.; Boerma, E. C.; Cecconi, M.; De Backer, D.; Shapiro, N. I.; Duranteau, J.; Pinsky, M. R.; Artigas, A.; Teboul, J. L.; Reiss, I. K. M.; et al. Second consensus on the assessment of sublingual microcirculation in critically ill patients: results from a task force of the European Society of Intensive Care Medicine. Intensive Care Med., 44(3):281-99, 2018.

Massey, M. J. \& Shapiro, N. I. A guide to human in vivo microcirculatory flow image analysis. Crit. Care, 20:35, 2016.

Massey, M. J.; Larochelle, E.; Najarro, G.; Karmacharla, A.; Arnold, R.; Trzeciak, S.; Angus, D. C. \& Shapiro, N. I. The microcirculation image quality score: development and preliminary evaluation of a proposed approach to grading quality of image acquisition for bedside videomicroscopy. J. Crit. Care, 28(6):913-7, 2013.

Sallisalmi, M.; Oksala, N.; Pettilä, V. \& Tenhunen, J. Evaluation of sublingual microcirculatory blood flow in the critically ill. Acta Anaesthesiol. Scand., 56(3):298-306, 2012.

Sherman, H.; Klausner, S. \& Cook, W. A. Incident dark-field illumination: a new method for microcirculatory study. Angiology, 22(5):295-303, 1971.

Spaide, R. F.; Fujimoto, J. G. \& Waheed, N. K. Image artifacts in optical coherence tomography angiography. Retina, 35(11):2163-80, 2015.

Trzeciak, S. \& Rivers, E. P. Clinical manifestations of disordered microcirculatory perfusion in severe sepsis. Crit. Care, 9(Suppl. 4):S20-6, 2005.

Tsai, A. G.; Johnson, P. C. \& Intaglietta, M. Oxygen gradients in the microcirculation. Physiol. Rev., 83(3):933-63, 2003.

van Elteren, H. A.; Ince, C.; Tibboel, D.; Reiss, I. K. M. \& de Jonge, R. C. J. Cutaneous microcirculation in preterm neonates: comparison between sidestreamdark field (SDF) and incident dark field (IDF) imaging. J. Clin. Monit. Comput., 29(5):543-8, 2015.

Corresponding author:

José Custódio Feres Vieira

Programa de Pós Graduação

PPG Ciência Cirúrgica Interdisciplinar

Universidade Federal de São Paulo (Unifesp)

São Paulo

BRASIL

E-mail: custodio.vieira@unifesp.br 